\title{
Impact of nutrients on insulin-like growth factor-l, insulin-like growth factor binding protein-3 and their ratio in African American and white males
}

\author{
Katharine M McGreevy ${ }^{1,2, *}$, Brian D Hoel ${ }^{3}$, Stuart R Lipsitz ${ }^{4}$ and David G Hoel ${ }^{1}$ \\ 'Department of Biostatistics, Bioinformatics, and Epidemiology, Medical University of South Carolina, Charleston, \\ SC, USA: ${ }^{2} \mathrm{New}$ Jersey Department of Health and Senior Services, Occupational Health Surveillance, PO Box 360, \\ Trenton, NJ 08625, USA: ${ }^{3}$ Department of Microbiology and Immunology, Medical University of South Carolina, \\ Charleston, SC, USA: ${ }^{4}$ Division of General Medicine, Harvard Medical School, Boston, MA, USA
}

Submitted 11 March 2005: Accepted 15 February 2006

\begin{abstract}
Objective: Higher levels of insulin-like growth factor-I (IGF-I) and lower levels of IGF binding protein-3 (IGFBP-3) have been associated with an increased risk of prostate cancer. Nutrition is known to partially regulate IGF levels and it is possible that nutritional factors mediate the impact of IGF levels on prostate cancer risk.

Design: A cross-sectional analysis of the impact of nutritional factors measured by a dietary questionnaire on plasma levels of IGF-I, IGFBP-3 and their molar ratio. Multiple linear regression analysis was used to test for effects of nutrients on IGF levels.

Setting: Prostate cancer screening at the Hollings Cancer Center in Charleston, South Carolina.

Subjects: Ninety-five African American and 138 white males aged 33-83 years attending the screening.

Results: In whites, intakes of total, saturated and monounsaturated fats were positively associated with an increase in the molar ratio, while there was no association in African Americans. In African Americans, we found that increasing intake of calcium and dairy servings was positively associated with IGF-I levels. Increased vegetable intake was positively associated with IGFBP-3 in African Americans, while there was no effect in whites. A higher percentage of alcohol in the total diet was significantly associated with a decrease in the molar ratio and an increase in IGFBP-3 in both groups.

Conclusions: Our results confirm previous findings of nutritional determinants of IGF levels. Additionally, we found the impact of several nutrients on IGF levels to be different in whites and African Americans, which warrants further investigation.
\end{abstract}

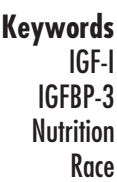

The insulin-like growth factor (IGF) system plays a role in stimulating cellular proliferation and inhibiting apoptosis $^{1,2}$. IGF-I has mitogenic and anti-apoptotic effects on normal and transformed prostate epithelial cells ${ }^{1,2}$. IGF binding protein-3 (IGFBP-3) binds to IGF-I, thereby inhibiting the mitogenic and anti-apoptotic effects of free IGF-I; it has also been demonstrated to induce cell death and be a negative regulator of cellular proliferation independent of IGF-I ${ }^{3-5}$. The mechanism relating IGF-I and IGFBP-3 to cancer has been reviewed previously ${ }^{2-6}$. High circulating levels of IGF- $\mathrm{I}^{7-13}$ and low levels of IGFBP- $3^{7,11,14}$ have been associated with an increased risk for the development of prostate cancer.

In vivo synthesis of IGF-I is stimulated by growth hormone and circulating plasma levels of IGFs are subject to complex physiological regulation ${ }^{15}$. The substantial inter-individual variation of IGF-I and IGFBP-3 levels is due to both genetic and non-genetic factors. Nutritional and lifestyle factors are known to regulate IGF-I levels $3,16-19$. Starvation, severe energy restriction and chronic energy restriction decrease circulating IGF-I levels in humans ${ }^{16,20,21}$. Protein-energy malnutrition decreases IGF-I levels and an increase in IGF-I levels is observed in response to improvements in both energy and protein intake during refeeding ${ }^{22}$.

Epidemiological studies indicate that nutrition plays a role in prostate cancer risk, although the mechanisms are not clear ${ }^{23,24}$. It is plausible that there is an interplay between diet and IGFs, and that the relationship between nutrition and prostate cancer may be partially mediated through the IGF system ${ }^{25}$. It has been demonstrated in animal studies that energy restriction can reduce the risk of 
cancer and inhibit tumour growth, and these effects were associated with a decrease in circulating IGF-I ${ }^{26,27}$. This evidence suggests that IGF may be the mediator in the relationship between diet and cancer.

The aims of the present study were to identify factors which influence IGF levels, a potentially modifiable suspected risk factor of prostate cancer, in African American and white males, and to determine if the effects of nutrients on IGF levels differ in the two racial groups. Previous studies have reported racial differences in IGF levels ${ }^{17,28-30}$ and there is evidence that age and anthropometric factors affect IGF levels differently in blacks and whites ${ }^{30,31}$.

In this paper we explore associations between IGF levels and nutrients which have previously been found to be associated with prostate cancer risk, specifically dairy, fat, lycopene, fruits and vegetables, zinc, selenium and vitamin $\mathrm{E}^{23,24,32-36}$. Further understanding the relationship between IGFs and nutrition may improve understanding of the aetiology of prostate cancer. In the USA during 1988-1992, African American males (180.6 per 100 000) had 31\% higher age-adjusted incidence rates than non-Hispanic white males (137.9 per 100000 ); and African American males (53.7 per $100000)$ had $120 \%$ higher age-adjusted mortality rates than non-Hispanic white males $(24.4 \text { per } 100000)^{37,38}$. The reasons for the drastic difference in incidence and mortality of prostate cancer between African Americans and US whites are unclear; however, nutritional and hormonal differences may explain some of the disparity.

\section{Materials and methods}

The study population was composed of 138 white males and 95 African American males aged 33-83 years, who were recruited during a free annual prostate cancer screening held at the Hollings Cancer Center at the Medical University of South Carolina (MUSC). This screening is open to the public and has been offered on an annual basis since 1992. Each year participants were recruited through newspaper, radio and television announcements, and males who attended the free screening in a previous year were mailed a letter inviting participation again. Males who reported a history of prostate cancer or who were found to have an abnormal digital rectal examination (DRE) or prostate-specific antigen (PSA) greater than $4.0 \mathrm{ng} \mathrm{ml}^{-1}$ at the screening were not included in this study. Informed consent was obtained from all participants. Participants reported dietary intake using the 2000 Brief Block Questionnaire, a validated dietary questionnaire ${ }^{39}$. The study was approved by the MUSC Institutional Review Board.

Blood samples for all subjects were drawn over a 2-day period in 2002 and stored at $-70^{\circ} \mathrm{C}$ until selected for testing. An individual aliquot of plasma from the three to six samples collected per patient was chosen, avoiding any lipaemic or haemolytic samples. Quantitative measurements of plasma IGF-I and IGFBP-3 levels were determined by enzyme-linked immunosorbent assay (ELISA) using the DSL-10-2800 ACTIVE ${ }^{\circledR}$ Non-Extraction IGF-I ELISA kit and the DSL-10-6600 ACTIVE ${ }^{\circledR}$ IGFBP-3 ELISA kit from Diagnostic Systems Laboratories, Inc. (Webster, TX, USA). All pre-treated samples and controls were assayed in duplicate, with the calculated mean used for data analysis. Plasma samples with a coefficient of variation of $5 \%$ or greater were repeated.

Plasma IGF levels were normally distributed; therefore, statistical procedures which assume normality were used. Multiple linear regression was used to test for the linear effects of nutrients on each of the outcomes (IGF-I, IGFBP3 and the molar ratio) while controlling for age, height and total energy separately for African Americans and whites. The molar ratio was used as an outcome as it is thought to represent the biologically active fraction of IGF-I.

Initially we modelled the effect of each dietary factor on IGF levels separately for blacks and whites. In the IGF models, a $t$-test was used to test for equal regression coefficients between African Americans and whites, which is equivalent to testing for no interaction between nutrient predictors and race ${ }^{40}$. We combined models across the two racial groups if the regression coefficients differed by less than $50 \%$. If the $t$-test for equal regression coefficients was rejected or the regression coefficients differed by more than $50 \%$ we carried out stratified analysis, since it is possible we lacked adequate power to detect a heterogeneous effect of dietary factors on IGF levels in the two race groups. Predicted mean values of IGF-I, IGFBP-3 and the molar ratio were obtained by quintiles of nutrients separately for African Americans and whites using the final separate regression models for each nutrient. The predicted value of each outcome (IGF-I, IGFBP-3 and the molar ratio) was obtained while controlling for overall mean age and height for nutrients within the range of reported intake for each racial group; therefore we did not extrapolate past the range of reported intake. The quintiles were calculated using the overall distribution of each nutrient.

\section{Results}

There were 233 males (59\% white and 41\% African American) in total with both complete dietary information and plasma levels of IGF-I and IGFBP-3 measured. Whites were older than African Americans: mean age 61 years versus 55 years, respectively $(P<0.01)$. There were no significant differences in baseline PSA level, DRE status, family history or current smoking status.

All results presented in Tables 1 and 2 are based on multivariate models controlling for age and height, and other nutrients also control for total energy intake as denoted. The nutritional factors we analysed were intakes of total energy, protein, calcium, phosphorus, vitamin D, total, saturated, polyunsaturated and monounsaturated 
Table 1 Predicted values of insulin-like growth factors for nutritional factors by race

\begin{tabular}{|c|c|c|}
\hline Nutrient quintile & Whites & African Americans \\
\hline \multicolumn{3}{|c|}{ IGF-I/IGFBP-3 molar ratio } \\
\hline \multicolumn{3}{|c|}{ Total fat $(\mathrm{g})$} \\
\hline$<35.1$ & $0.110(0.095,0.125)$ & $0.135(0.115,0.154)$ \\
\hline $35.1-46.2$ & $0.117(0.108,0.126)$ & $0.134(0.123,0.146)$ \\
\hline $46.3-60.8$ & $0.122(0.116,0.128)$ & $0.134(0.126,0.142)$ \\
\hline $60.9-80.6$ & $0.129(0.122,0.135)$ & $0.134(0.123,0.144)$ \\
\hline $80.7-165.9$ & $0.149(0.127,0.171)$ & $0.133(0.107,0.159)$ \\
\hline$P$-value $\dagger$ & 0.03 & 0.94 \\
\hline \multicolumn{3}{|l|}{ Saturated fat $(\mathrm{g})$} \\
\hline$<11.3$ & $0.111(0.097,0.126)$ & $0.131(0.113,0.148)$ \\
\hline $11.3-15.3$ & $0.118(0.108,0.127)$ & $0.132(0.121,0.143)$ \\
\hline $15.4-20.3$ & $0.122(0.116,0.129)$ & $0.134(0.126,0.141)$ \\
\hline $20.4-28.9$ & $0.129(0.122,0.135)$ & $0.135(0.125,0.146)$ \\
\hline $29.0-56.2$ & $0.146(0.126,0.165)$ & $0.139(0.114,0.163)$ \\
\hline$P$-value $\dagger$ & $<0.05$ & 0.70 \\
\hline \multicolumn{3}{|c|}{ Monounsaturated fat (g) } \\
\hline$<12.5$ & $0.112(0.099,0.125)$ & $0.131(0.114,0.148)$ \\
\hline $12.5-17.4$ & $0.118(0.110,0.127)$ & $0.132(0.122,0.143)$ \\
\hline $17.5-22.1$ & $0.123(0.116,0.129)$ & $0.134(0.126,0.141)$ \\
\hline $22.2-30.0$ & $0.128(0.122,0.134)$ & $0.135(0.125,0.144)$ \\
\hline $30.1-66.7$ & $0.147(0.125,0.168)$ & $0.138(0.112,0.164)$ \\
\hline$P$-value $\dagger$ & $<0.05$ & 0.73 \\
\hline \multicolumn{3}{|c|}{ Fibre fruit/vegetable (g) } \\
\hline$<3.56$ & $0.127(0.118,0.136)$ & $0.142(0.133,0.151)$ \\
\hline $3.56-5.45$ & $0.126(0.119,0.133)$ & $0.139(0.130,0.148)$ \\
\hline $5.46-7.94$ & $0.125(0.120,0.131)$ & $0.136(0.129,0.144)$ \\
\hline $7.95-11.10$ & $0.125(0.118,0.131)$ & $0.133(0.125,0.140)$ \\
\hline $11.11-32.52$ & $0.122(0.106,0.138)$ & $0.117(0.100,0.133)$ \\
\hline$P$-value $\dagger$ & 0.67 & $<0.05$ \\
\hline \multicolumn{3}{|c|}{$\%$ of diet from fatł } \\
\hline$<24.08$ & $0.113(0.100,0.124)$ & $0.136(0.122,0.149)$ \\
\hline $24.08-29.50$ & $0.121(0.114,0.128)$ & $0.134(0.126,0.142)$ \\
\hline $29.51-34.18$ & $0.124(0.119,0.130)$ & $0.133(0.126,0.140)$ \\
\hline $34.19-39.26$ & $0.128(0.122,0.134)$ & $0.132(0.123,0.141)$ \\
\hline $39.27-54.75$ & $0.136(0.126,0.145)$ & $0.131(0.118,0.144)$ \\
\hline$P$-value $†$ & 0.02 & 0.68 \\
\hline \multicolumn{3}{|l|}{ IGF-I $\left(n g m I^{-1}\right)$} \\
\hline \multicolumn{3}{|l|}{ Calcium (mg) } \\
\hline$<382.9$ & $134.0(120.7,147.2)$ & $114.4(101.4,127.4)$ \\
\hline $382.9-489.5$ & $134.2(123.6,144.8)$ & $121.0(111.4,130.7)$ \\
\hline $489.6-629.8$ & $134.5(125.9,143.0)$ & $125.5(117.2,133.8)$ \\
\hline $629.9-850.6$ & $134.8(126.9,142.8)$ & $131.9(122.3,141.6)$ \\
\hline $850.7-2130.1$ & $135.9(117.7,154.2)$ & $158.7(128.0,186.4)$ \\
\hline$P$-value $\dagger$ & 0.89 & 0.04 \\
\hline \multicolumn{3}{|c|}{ Dairy servings/daył } \\
\hline$<0.4$ & $133.6(121.9,145.3)$ & $119.6(109.5,129.7)$ \\
\hline $0.4-0.7$ & $134.0(124.2,143.7)$ & $123.2(114.7,131.7)$ \\
\hline $0.8-1.1$ & $134.3(126.1,142.5)$ & $127.2(119.1,135.3)$ \\
\hline $1.2-1.6$ & $134.8(127.0,142.5)$ & $131.8(122.3,141.2)$ \\
\hline $1.7-5.4$ & $136.4(120.0,152.8)$ & $153.0(130.4,175.7)$ \\
\hline$P$-value $\dagger$ & 0.82 & 0.03 \\
\hline \multicolumn{3}{|l|}{$\%$ of alcoholł } \\
\hline 0 & $136.4(127.2,145.6)$ & $130.3(121.4,139.1)$ \\
\hline $0.1-0.3$ & $136.4(127.3,145.5)$ & $130.0(121.3,138.7)$ \\
\hline $0.4-3.1$ & $136.0(127.4,144.7)$ & $128.5(120.2,136.8)$ \\
\hline $3.2-13.0$ & $134.7(126.9,142.6)$ & $122.2(113.3,131.1)$ \\
\hline $13.1-55.0$ & $129.3(112.1,146.5)$ & $100.8(80.8,120.8)$ \\
\hline$P$-value & 0.5 & 0.04 \\
\hline \multicolumn{3}{|c|}{ IGFBP-3 (ng mI $\left.I^{-1}\right)$} \\
\hline \multicolumn{3}{|c|}{ Polyunsaturated fat (g) } \\
\hline$<6.8$ & $3929(3598,4260)$ & $3015(2618,3412)$ \\
\hline $6.8-9.3$ & 3919 (3696, 4142) & 3231 (2983, 3479) \\
\hline $9.4-12.3$ & $3911(3744,4077)$ & 3397 (3223, 3572) \\
\hline $12.4-15.8$ & 3901 (3724, 4079) & $3586(3385,3787)$ \\
\hline $15.9-40.5$ & $3860(3232,4488)$ & $4062(3535,4590)$ \\
\hline$P$-value $†$ & 0.88 & 0.02 \\
\hline
\end{tabular}

Fibre fruit/vegetable $(\mathrm{g})$ 
Table 1. Continued

\begin{tabular}{|c|c|c|}
\hline Nutrient quintile & Whites & African Americans \\
\hline$<3.56$ & $3915(3663,4167)$ & $3166(2912,3421)$ \\
\hline $3.56-5.45$ & $3911(3724,4097)$ & $3279(3075,3482)$ \\
\hline $5.46-7.94$ & $3908(3746,4069)$ & $3374(3199,3548)$ \\
\hline $7.95-11.10$ & $3903(3719,4087)$ & $3496(3328,3665)$ \\
\hline $11.11-32.52$ & $3890(3433,4347)$ & $4034(3609,4459)$ \\
\hline$P$-value & 0.94 & $<0.01$ \\
\hline \multicolumn{3}{|l|}{ Fibre $(\mathrm{g})$} \\
\hline$<8.7$ & $3972(3696,4248)$ & $3137(2823,3450)$ \\
\hline $8.7-12.5$ & $3942(3741,4144)$ & $3287(3069,3505)$ \\
\hline $12.6-16.0$ & $3917(3754,4081)$ & $3398(3223,3573)$ \\
\hline $16.1-21.7$ & $3886(3710,4062)$ & $3537(3354,3719)$ \\
\hline $21.8-55.5$ & $3758(3217,4299)$ & $4131(3539,4722)$ \\
\hline$P$-value $\dagger$ & $0.57^{*}$ & 0.02 \\
\hline \multicolumn{3}{|c|}{ Vegetable servings/day } \\
\hline$<1.1$ & $3890(3651,4130)$ & $3296(3088,3505)$ \\
\hline $1.1-2.0$ & $3896(3704,4088)$ & $3366(3181,3551)$ \\
\hline $2.1-3.1$ & $3902(3738,4065)$ & $3433(3266,3601)$ \\
\hline $3.2-4.9$ & $3909(3741,4078)$ & $3526(3349,3702)$ \\
\hline $5.0-17.4$ & $3945(3430,4459)$ & $3985(3506,4463)$ \\
\hline$P$-value $†$ & 0.87 & 0.03 \\
\hline
\end{tabular}

IGF-I - insulin-like growth factor-I; IGFBP-3 - insulin-like growth factor binding protein-3.

Values in parentheses are $95 \%$ confidence intervals.

${ }^{*} P<0.05$ for $t$-test of equal slopes between blacks and whites.

$\dagger$ The $P$-values reflect the test for trend between dietary factor and outcome by race.

$\ddagger$ Indicates predicted values are based on multivariate models controlling for age and height; while for unmarked nutrients the predicted values are based on multivariate models controlling for age, height and total energy intake.

Table 2 Predicted values of insulin-like growth factors for nutritional factors by race $\dagger$

\begin{tabular}{|c|c|c|c|}
\hline Nutrient quintile & Whites & African Americans & $P$-value $\neq$ \\
\hline \multicolumn{4}{|l|}{ 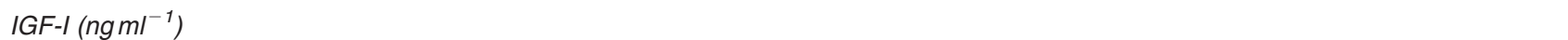 } \\
\hline \multicolumn{4}{|l|}{ Phosphorus (mg) } \\
\hline$<680.7$ & $118.6(104.1,133.1)$ & $109.8(94.6,124.9)$ & \multirow[t]{5}{*}{0.02} \\
\hline $680.7-825.3$ & $124.9(114.5,135.2)$ & $118.1(107.7,128.4)$ & \\
\hline $825.4-1073.3$ & $130.9(123.3,138.5)$ & $124.1(115.3,133.0)$ & \\
\hline $1073.4-1323.4$ & $138.6(130.6,146.7)$ & $131.8(121.5,142.2)$ & \\
\hline $1323.5-2691.1$ & $163.5(138.4,188.5)$ & $149.5(127.7,171.3)$ & \\
\hline \multicolumn{4}{|l|}{ Protein $(\mathrm{g})$} \\
\hline$<40.1$ & $121.8(108.3,135.3)$ & $113.0(98.8,127.2)$ & \multirow[t]{5}{*}{0.04} \\
\hline $40.1-48.2$ & $127.2(117.5,136.8)$ & $119.7(109.7,129.7)$ & \\
\hline $48.3-59.0$ & $130.5(122.6,138.4)$ & $123.1(114.2,132.0)$ & \\
\hline $59.1-80.9$ & $136.3(128.9,143.8)$ & $128.9(119.4,138.4)$ & \\
\hline $81.0-181.9$ & $158.6(134.7,182.5)$ & $143.2(124.1,162.2)$ & \\
\hline \multicolumn{4}{|c|}{ IGF-I/IGFBP-3 molar ratio } \\
\hline \multicolumn{4}{|l|}{$\%$ of alcohol§ } \\
\hline 0 & $0.132(0.126,0.139)$ & $0.138(0.131,0.145)$ & \multirow[t]{5}{*}{$<0.01$} \\
\hline $0.1-0.3$ & $0.132(0.126,0.139)$ & $0.137(0.131,0.144)$ & \\
\hline $0.4-3.1$ & $0.131(0.125,0.137)$ & $0.136(0.130,0.143)$ & \\
\hline $3.2-13.0$ & $0.127(0.121,0.132)$ & $0.132(0.125,0.139)$ & \\
\hline $13.1-55.0$ & $0.108(0.097,0.119)$ & $0.116(0.104,0.128)$ & \\
\hline IGFBP-3 $(n g m)^{-1}$ & & & \\
\hline$\%$ of alcohol§ & & & \\
\hline 0 & $3765(3593,3937)$ & $3348(3164,3532)$ & \multirow[t]{5}{*}{0.02} \\
\hline $0.1-0.3$ & $3768(3597,3939)$ & $3351(3167,3535)$ & \\
\hline $0.4-3.1$ & $3786(3623,3949)$ & 3369 (3189, 3549) & \\
\hline $3.2-13.0$ & $3861(3712,4010)$ & $3444(3262,3626)$ & \\
\hline $13.1-55.0$ & $4169(3871,4467)$ & $3700(3386,4014)$ & \\
\hline
\end{tabular}

IGF-I - insulin-like growth factor-I; IGFBP-3 - insulin-like growth factor binding protein-3.

Values in parentheses are $95 \%$ confidence intervals.

† Predicted values are based on a combined model controlling for race, age and height.

$\ddagger$ The $P$-values from the combined model reflect the trend for the association between nutrient and outcome, which is the same across race.

$\S$ Indicates predicted values are based on multivariate models controlling for age and height; while for unmarked nutrients the predicted values are based on multivariate models controlling for age, height and total energy intake. 
fats, fruit and vegetables, fibre, alcohol, lycopene, vitamin E, zinc and selenium.

Preliminary analyses (not shown) indicated that both age and height were associated with IGF levels in this population. The tables include nutrients that had a linear association with one of the three outcomes (IGF-I, IGFBP3, molar ratio) for either African Americans or whites. The $P$-value shown below the IGF levels is associated with the continuous nutrient in each of the models for each race-stratified model. An asterisk on the $P$-value of whites indicates that the $t$-test for equal slopes of the nutrient between African Americans and whites was rejected. The results for the association between IGF outcomes and total nutrients, which represents intake from both supplements and food groups, are similar to those for food intake alone and are not shown.

There was no linear association between total energy intake and IGF levels in African Americans or whites at the 0.05 level of significance. Intakes of total fat, saturated fat and monounsaturated fat, and increasing percentage of total energy intake from fat, were positively associated with a linear increase in the molar ratio in whites, while there was no such effect in African Americans. The highest quintile of total fat intake was associated with a $35 \%$ higher molar ratio compared with the lowest quintile in whites. Polyunsaturated fat intake showed a linear positive association with increasing IGFBP-3 levels in African Americans (the highest quintile had 35\% higher IGFBP-3 levels than the lowest quintile), while there was no association in whites.

A higher percentage of alcohol in the total diet was significantly associated with a linear decrease in the molar ratio and a linear increase in IGFBP-3 levels in both African Americans and whites. In African Americans, a higher percentage of alcohol in the diet resulted in a significant decrease in IGF-I levels. A higher intake of protein was associated with a positive increase in IGF-I levels in both African Americans and whites.

Dairy intake appeared to have an effect in African Americans but not in whites. In African Americans, we found that increasing intake of calcium was positively associated with IGF-I levels, while there was no association in whites. African American males who reported daily intake of calcium between 851 and $2130 \mathrm{mg}$ had 39\% higher IGF-I levels than those with less than $383 \mathrm{mg}$. Increased dairy servings per day was also positively associated with IGF-I levels in African Americans (a 28\% increase in the highest compared with the lowest quintile), while there was no such effect in whites. Phosphorus had a positive association with IGF-I in both African Americans and whites in a combined model while controlling for age, height, total energy intake and race.

We also examined the impact of fruit, vegetable and fibre intake on IGF levels. In African Americans, there was a positive linear association between fibre intake (from vegetables and fruits) and IGFBP-3 and an inverse linear association with the molar ratio, while there was no association between fibre intake and IGF levels in whites. Increased fibre intake from all sources was also positively associated with IGFBP-3 levels in African Americans: there was a 32\% increase in IGFBP-3 levels in the highest quintile compared with the lowest quintile of fibre intake. The test of equal slopes of fibre on IGF levels between African Americans and whites was rejected. In African Americans, increased vegetable servings per day resulted in a positive linear increase in IGFBP-3 levels; those who had more than 5 servings of vegetables a day had 21\% higher IGFBP-3 levels than those with less than 1.1 servings per day. There was no association between fruit servings per day and IGF levels in whites or African Americans. There was no association between any of the IGF levels and lycopene, vitamin E, zinc or selenium in African Americans or whites at the 0.05 level of significance. As an exploratory analysis we investigated associations between other dietary factors (cysteine, lutein, cryptoxanthin, retinol, and $\alpha$ - and $\beta$-carotene) and IGF levels and found no statistically significant linear associations.

\section{Discussion}

This was an exploratory analysis of the association between IGF-I, IGFBP-3 and their molar ratio with nutrients in race-stratified models. Since we examined the relationship of several nutrients with IGF levels, associations could occur by chance and should be replicated in other studies.

In this cross-sectional analysis of a community sample of middle-aged to elderly African American and white males, we found associations between several nutritional factors, some previously linked with prostate cancer, and IGF-I, IGFBP-3 and the molar ratio. Many nutrients had a strong effect on IGF levels in one racial group but no impact in the other. Alcohol, phosphorus and protein were the only dietary factors that had a similar and significant impact on levels in both racial groups. Calcium, fibre, vegetable and fruit intakes had an effect in African Americans, but no effect in whites. Total, saturated and monounsaturated fat intakes affected IGF levels in whites, but not African Americans.

This study is unique because we explored the impact of nutrients on IGF levels in race-stratified models. Previous analyses on the impact of nutritional factors, measured by a uniform dietary questionnaire, on circulating IGF-I and IGFBP-3 levels have assumed homogeneity of effects across racial groups. One previous study analysed associations of IGF-I with macronutrients in each racial group of white European, African Caribbean and Pakistani males and females ${ }^{41}$. However, each racial group in that study was administered a different food-frequency questionnaire, while in our study all participants were administered the same dietary questionnaire. 
The effect of alcohol on the molar ratio is very similar in African Americans and whites, with a decrease of 18\% in whites and of 21\% in African Americans in the highest quintile compared with the lowest. Our study is consistent with two previous studies which found an inverse association between alcohol and IGF-I levels ${ }^{42,43}$ and also with the finding that patients with long-term liver damage have decreased IGF-I levels ${ }^{3,44}$. One study found no association between alcohol and IGF-I ${ }^{45}$, while another found a positive association although the age-adjusted mean IGF-I levels were actually higher for those who consumed the fewest amount of drinks compared with those who consumed the most ${ }^{46}$. Our finding of a positive association between IGFBP-3 levels and alcohol intake is consistent with a previous study on women ${ }^{47}$.

Previous studies on the association between intake of total energy and IGF levels have been inconsistent ${ }^{18,47-49}$. Our failure to find an association between intake of total energy and IGF levels is consistent with two studies which also failed to find an association between total energy intake and IGF-I, IGFBP-3 or the molar ratio ${ }^{48,49}$. Giovannucci et al. ${ }^{49}$ did find a positive association between IGF-I and total energy intake in a subset of males with body mass index less than $25 \mathrm{~kg} \mathrm{~m}^{-2}$; we did not find this association in the corresponding subset of males in our study. In a study of women IGF-I and IGFBP-3 were positively associated with total energy intake ${ }^{47}$. Although it is clear that chronic/severe energy restriction decreases IGF-I levels ${ }^{16,20,21}$ and there is evidence that overnutrition increases IGF-I, it may be that energy intake does not have an effect on IGF levels within the normal range of intake.

The effect of dairy and calcium on IGF-I levels in African Americans is noteworthy. Our results in African American males are consistent with several previous studies which have found an association between increased consumption of dairy products and IGF-I levels ${ }^{47-52}$; one study found an increase that was not significant ${ }^{42}$. In a study on women, food sources of calcium and vitamin D (dairy, milk) were positively and significantly associated with increased IGF-I levels ${ }^{47}$. Our finding of a positive association between phosphorus and IGF-I is consistent with a previous study ${ }^{49}$.

Our results on total fat, saturated fat and monounsaturated fat in whites are consistent with previous studies which found increased intake of fat to result in an increase in IGF-I levels, an increase in the molar ratio or a decrease in IGFBP- $3^{18,41,47}$. However, one study did not find an association between either IGF-I or the molar ratio and saturated fat, monounsaturated fat or polyunsaturated fat ${ }^{42}$. IGF-I levels were found to be positively correlated with the consumption of fats and oils, while IGFBP-3 levels were found to be inversely correlated with energy intake from lipids, in healthy Greek males and females ${ }^{18}$. Heald et al. found that IGF-I was positively associated with dietary fat and saturated fat; the relationship appeared to be nonlinear with IGF-I levels increasing until they decreased slightly in the highest quintile ${ }^{41}$. Higher intakes of total fat, animal fat, saturated fat and monounsaturated fat were inversely associated with IGFBP-3 in a study conducted on females ${ }^{47}$. Our detection of a positive association between IGFBP-3 and polyunsaturated fat in African Americans is consistent with one previous study ${ }^{48}$, but another study in females found no association between intake of polyunsaturated fat and IGFBP-3 levels ${ }^{47}$.

Our finding that increased vegetable servings and fibre from the diet increase IGFBP-3 levels in African American males is noteworthy. These results on vegetable intake are consistent with Gunnell et al. ${ }^{48}$ who found that increased vegetable intake decreased the molar ratio, although other studies have failed to detect an association between intake of fruits or vegetables and IGF-I or IGFBP-3 levels ${ }^{18,47}$.

Our failure to find an association between lycopene and either IGF-I or IGFBP-3 levels is not supported by previous studies. One study found a positive association between lycopene intake and IGFBP-3 levels in women ${ }^{47}$ and another study an inverse association between increased consumption of cooked tomatoes with IGF-I levels ${ }^{42}$. It is possible that our failure to find an association between lycopene and IGF levels is because the intake is too low in our population. Mediterranean diets contain a greater intake of tomatoes and our population might not be consuming sufficiently high levels to have an effect. In the study by Mucci et al., males consumed on average 13.2 servings of cooked tomatoes per month which translates into approximately $28000 \mu \mathrm{g}$ of lycopene per day ${ }^{42}$. The average reported daily intake of lycopene among males in our study is much lower at $4084 \mu \mathrm{g}$. It is also much lower than the daily lycopene intake reported by women in the study of Holmes et al; $84 \%$ of our population had lycopene intake lower than the first quintile $(5708 \mu \mathrm{g})$ in this previous analysis ${ }^{47}$.

Our finding of a positive association between protein intake and IGF-I levels in African Americans and whites is consistent with previous studies. Protein-energy malnutrition decreases IGF-1 levels and an increase in IGF-1 levels is observed in response to improvements in both energy and protein intake during refeeding ${ }^{22,47}$. We found no association between zinc and any of the IGFs, while previous analyses found an increase in IGF-I with zinc from food sources ${ }^{47,49}$.

It is important to note that many dietary factors known to be associated with prostate cancer were found to be associated with IGF levels in this analysis. The most notable findings included the positive association between dairy (calcium, phosphorus, dairy servings) and IGF-I levels in African Americans, as well as the positive association between phosphorus and IGF-I in whites. High intake of calcium has been found to be associated with an increased risk of prostate cancer and the risk appears to be stronger for advanced fatal prostate cancer among older males, suggesting that it influences disease progression $^{24,53-56}$. The positive association between 
dietary fat and the molar ratio in whites is of interest as total fat, saturated fat and animal fat have been found to increase prostate cancer risk ${ }^{24}$. The positive association of fibre, fruits and vegetables with IGFBP-3 levels in African Americans is of interest. A review of the nutrition and prostate cancer literature concluded that the consumption of cooked tomatoes and diets high in vegetables are likely protective against the risk of prostate cancer ${ }^{24}$.

An advantage of the present study is that $41 \%$ of the population were African Americans, which enabled us to stratify on race and explore the effects of nutrients on IGF levels within two racial groups. It has been demonstrated that there are significant racial differences in IGF levels; therefore failing to control for race could confound the relationship between nutrients and IGF levels. We found race to modify the effect of several nutrients on IGF levels. Although many nutrients had an impact on IGF levels in one racial group while not in the other, the test for equal slopes between African Americans and whites was not rejected for many nutrients. This failure to detect an interaction for many nutrients may be due to a lack of power. A limitation of our study is the cross-sectional design, which prohibits the ability to discern the temporal relationship in the effect of diet modification of IGF levels. Another limitation of this study is we may have lacked adequate power to detect associations between nutritional factors and outcomes, as well as to detect a statistically significant heterogeneity of effect between nutrients and IGF across the two racial groups, due to the small sample size.

In conclusion, this analysis further supports that IGF levels, a potential risk factor for prostate cancer, may be modified through nutrition. Our finding of race-specific effects of nutrition on IGF levels is novel and warrants further investigation.

\section{Acknowledgements}

Source of funding: This research is supported by funds from the US Department of Defense, grant number N6311602MD200.

Conflict of interest: None declared.

Author roles: K.M.M. developed the research idea, designed the study and acquired data with assistance of her mentor, D.G.H. B.D.H. oversaw and conducted laboratory analyses, and K.M.M. assisted. S.R.L. and K.M.M. planned the statistical methodology, analysed and interpreted the data. S.R.L., D.G.H., B.D.H. and K.M.M. approved the version to be published.

\section{References}

1 Pollak MN, Schernhammer ES, Hankinson SE. Insulin-like growth factors and neoplasia. Nature Reviews. Cancer 2004; 4(7): 505-18.

2 Pollak M. Insulin-like growth factor physiology and cancer risk. European Journal of Cancer 2000; 36(10): 1224-8.
3 Yu H, Rohan T. Role of the insulin-like growth factor family in cancer development and progression. Journal of the National Cancer Institute 2000; 92(18): 1472-89.

4 Rajah R, Valentinis B, Cohen P. Insulin-like growth factor (IGF)-binding protein-3 induces apoptosis and mediates the effects of transforming growth factor- $\beta 1$ on programmed cell death through a p53- and IGF-independent mechanism. Journal of Biological Chemistry 1997; 272(18): 12181-8.

5 Grimberg A. P53 and IGFBP-3: apoptosis and cancer protection. Molecular Genetics \& Metabolism 2000; 70(2): 85-98.

6 Pollak M. Insulin-like growth factors and prostate cancer. Epidemiologic Reviews 2001; 23(1): 59-66.

7 Chan JM, Stampfer MJ, Giovannucci E, Gann PH, Ma J, Wilkinson $\mathrm{P}$, et al. Plasma insulin-like growth factor-I and prostate cancer risk: a prospective study. Science 1998; 279(5350): 563-6.

8 Harman SM, Metter EJ, Blackman MR, Landis PK, Carter HB; Baltimore Longitudinal Study on Aging. Serum levels of insulin-like growth factor I (IGF-I), IGF-II, IGF-binding protein-3, and prostate-specific antigen as predictors of clinical prostate cancer. Journal of Clinical Endocrinology and Metabolism 2000; 85(11): 4258-65.

9 Stattin P, Bylund A, Rinaldi S, Biessy C, Dechaud H, Stenman UH, et al. Plasma insulin-like growth factor-I, insulin-like growth factor-binding proteins, and prostate cancer risk: a prospective study. Journal of the National Cancer Institute 2000; 92(23): 1910-7.

10 Djavan B, Bursa B, Seitz C, Soeregi G, Remzi M, Basharkhah A, et al. Insulin-like growth factor 1 (IGF-1), IGF-1 density, and IGF-1/PSA ratio for prostate cancer detection. Urology 1999; 54(4): 603-6.

11 Chokkalingam AP, Pollak M, Fillmore CM, Gao YT, Stanczyk FZ, Deng J, et al. Insulin-like growth factors and prostate cancer: a population-based case-control study in China. Cancer Epidemiology, Biomarkers \& Prevention 2001; 10(5): 421-7.

12 Mantzoros CS, Tzonou A, Signorello LB, Stampfer M, Trichopoulos D, Adami HO. Insulin-like growth factor 1 in relation to prostate cancer and benign prostatic hyperplasia. British Journal of Cancer 1997; 76(9): 1115-8.

13 Wolk A, Mantzoros CS, Andersson SO, Bergstrom R, Signorello LB, Lagiou $\mathrm{P}$, et al. Insulin-like growth factor 1 and prostate cancer risk: a population-based, case-control study. Journal of the National Cancer Institute 1998; 90(12): 911-5.

14 Chan JM, Stampfer MJ, Ma J, Gann P, Gaziano JM, Pollak M, et al. Insulin-like growth factor-I (IGF-I) and IGF binding protein-3 as predictors of advanced-stage prostate cancer. Journal of the National Cancer Institute 2002; 94(14): 1099-106.

15 Pollak M, Beamer W, Zhang JC. Insulin-like growth factors and prostate cancer. Cancer Metastasis Reviews 1999; 17(4): 383-90.

16 Thissen JP, Ketelslegers JM, Underwood LE. Nutritional regulation of the insulin-like growth factors. Endocrine Reviews 1994; 15(1): 80-101.

17 Platz EA, Pollak MN, Rimm EB, Majeed N, Tao YZ, Willett WC, et al. Racial variation in insulin-like growth factor-1 and binding protein-3 concentrations in middle-aged men. Cancer Epidemiology, Biomarkers \& Prevention 1999; 8(12): $1107-10$.

18 Kaklamani VG, Linos A, Kaklamani E, Markaki I, Koumantaki Y, Mantzoros CS. Dietary fat and carbohydrates are independently associated with circulating insulin-like growth factor 1 and insulin-like growth factor-binding protein 3 concentrations in healthy adults. Journal of Clinical Oncology 1999; 17(10): 3291-8.

19 Harrela M, Koistinen H, Kaprio J, Lehtovirta M, Tuomilehto J, Eriksson J, et al. Genetic and environmental components of interindividual variation in circulating levels of IGF-I, IGF-II, 
IGFBP-1, and IGFBP-3. Journal of Clinical Investigation 1996; 98(11): 2612-5.

20 Ketelslegers JM, Maiter D, Maes M, Underwood LE, Thissen JP. Nutritional regulation of insulin-like growth factor-I. Metabolism: Clinical and Experimental 1995; 44(10 Suppl. 4): 50-7.

21 Ketelslegers JM, Maiter D, Maes M, Underwood LE, Thissen JP. Nutritional regulation of the growth hormone and insulinlike growth factor-binding proteins. Hormone Research 1996; 45(3-5): 252-7.

22 Soliman AT, Hassan AE, Aref MK, Hintz RL, Rosenfeld RG, Rogol AD. Serum insulin-like growth factors I and II concentrations and growth hormone and insulin responses to arginine infusion in children with protein-energy malnutrition before and after nutritional rehabilitation. Pediatric Research 1986; 20(11): 1122-30.

23 Clinton SK, Giovannucci E. Diet, nutrition, and prostate cancer. Annual Review of Nutrition 1998; 18: 413-40.

24 World Cancer Research Fund (WCRF)/American Institute for Cancer Research (AICR). Food, Nutrition and the Prevention of Cancer: A Global Perspective. Washington, DC: WCRF/AICR, 1997

25 Dunn S, Kari F, French J, Leininger J, Travlos G, Wilson R, et al. Dietary restriction reduces insulin-like growth factor I levels, which modulates apoptosis, cell proliferation, and tumor progression in p53-deficient mice. Cancer Research 1997; 57(21): 4667-72.

26 Mukherjee P, Sotnikov AV, Mangian HJ, Zhou JR, Visek WJ, Clinton SK. Energy intake and prostate tumor growth, angiogenesis, and vascular endothelial growth factor expression. Journal of the National Cancer Institute 1999; 91(6): 512-23.

27 Kritchevsky D. Caloric restriction and experimental carcinogenesis. Advances in Experimental Medicine and Biology 1992; 322: 131-41.

28 Tricoli JV, Winter DL, Hanlon AL, Raysor SL, Watkins-Bruner $\mathrm{D}$, Pinover $\mathrm{WH}$, et al. Racial differences in insulin-like growth factor binding protein-3 in men at increased risk of prostate cancer. Urology 1999; 54(1): 178-82.

29 Wright NM, Renault J, Willi S, Veldhuis JD, Pandey JP, Gordon L, et al. Greater secretion of growth hormone in black than in white men: possible factor in greater bone mineral density - a clinical research center study. Journal of Clinical Endocrinology and Metabolism 1995; 80(8): 2291-7.

30 DeLellis K, Rinaldi S, Kaaks R, Kolonel L, Henderson B, Le Marchand L. Dietary and lifestyle correlates of plasma insulin-like growth factor-I (IGF-I) and IGF binding protein3 (IGFBP-3): The Multiethnic Cohort. Cancer Epidemiology, Biomarkers \& Prevention 2004; 13(9): 1444-51.

31 McGreevy K, Hoel B, Lipsitz S, Bissada N, Hoel D. Racial and anthropometric differences in plasma levels of insulin like growth factor I and insulin like growth factor binding protein-3. Urology 2005; 66(3): 587-92.

32 Saxe GA, Hebert JR, Carmody JF, Kabat-Zinn J, Rosenzweig $\mathrm{PH}$, Jarzobski D, et al. Can diet in conjunction with stress reduction affect the rate of increase in prostate specific antigen after biochemical recurrence of prostate cancer? Journal of Urology 2001; 166(6): 2202-7.

33 Heinonen OP, Albanes D, Virtamo J, Taylor PR, Huttunen JK, Hartman AM, et al. Prostate cancer and supplementation with $\alpha$-tocopherol and $\beta$-carotene: incidence and mortality in a controlled trial. Journal of the National Cancer Institute 1998; 90(6): 440-6.

34 Nomura AM, Lee J, Stemmermann GN, Combs GF Jr. Serum selenium and subsequent risk of prostate cancer. Cancer Epidemiology, Biomarkers \& Prevention 2000; 9(9): 883-7.

35 Willett WC, Polk BF, Morris JS, Stampfer MJ, Pressel S, Rosner $\mathrm{B}$, et al. Prediagnostic serum selenium and risk of cancer. Lancet 1983; 2(8342): 130-4.
36 Gann PH, Ma J, Giovannucci E, Willett W, Sacks FM, Hennekens $\mathrm{CH}$, et al. Lower prostate cancer risk in men with elevated plasma lycopene levels: results of a prospective analysis. Cancer Research 1999; 59(6): 1225-30.

37 National Institutes of Health. Racial/Ethnic Patterns of Cancer in the United States, 1988-1992. Bethesda, MD: National Cancer Institute, 1996.

38 Stanford JL, Stephenson RA, Coyle LM, Cerhan J, Correa R, Eley JW, et al. Prostate Cancer Trends 1973-1995. Report No. 99-4543. Bethesda, MD: National Cancer Institute, 1999.

39 Block G, Hartman AM, Naughton D. A reduced dietary questionnaire: development and validation. Epidemiology 1990; 1(1): 58-64.

40 Draper N, Smith H. Applied Regression Analysis, 2nd ed. New York: John Wiley and Son, 1981.

41 Heald AH, Cade JE, Cruickshank JK, Anderson S, White A, Gibson JM. The influence of dietary intake on the insulin-like growth factor (IGF) system across three ethnic groups: a population-based study. Public Health Nutrition 2003; 6(2): $175-80$

42 Mucci LA, Tamimi R, Lagiou P, Trichopoulou A, Benetou V, Spanos E, et al. Are dietary influences on the risk of prostate cancer mediated through the insulin-like growth factor system? BJU International 2001; 87(9): 814-20.

43 Teramukai S, Rohan T, Eguchi H, Oda T, Shinchi K, Kono S. Anthropometric and behavioral correlates of insulin-like growth factor I and insulin-like growth factor binding protein 3 in middle-aged Japanese men. American Journal of Epidemiology 2002; 156(4): 344-8.

44 Santolaria F, Gonzalez-Gonzalez G, Gonzalez-Reimers E, Martinez-Riera A, Milena A, Rodgiguez-Moreno F, et al. Effects of alcohol and liver cirrhosis on the GH-IGF-I axis. Alcohol and Alcoholism 1995; 30(6): 703-8.

45 Kaklamani VG, Linos A, Kaklamani E, Markaki I, Mantzoros C. Age, sex, and smoking are predictors of circulating insulin-like growth factor 1 and insulin-like growth factor-binding protein 3. Journal of Clinical Oncology 1999; 17(3): 813-7.

46 Goodman-Gruen D, Barrett-Connor E. Epidemiology of insulin-like growth factor-I in elderly men and women. The Rancho Bernardo Study. American Journal of Epidemiology 1997; 145(11): 970-6.

47 Holmes MD, Pollak MN, Willett WC, Hankinson SE. Dietary correlates of plasma insulin-like growth factor I and insulinlike growth factor binding protein 3 concentrations. Cancer Epidemiology, Biomarkers \& Prevention 2002; 11(9): 852-61.

48 Gunnell D, Oliver SE, Peters TJ, Donovan JL, Persad R, Maynard M, et al. Are diet-prostate cancer associations mediated by the IGF axis? A cross-sectional analysis of diet, IGF-I and IGFBP-3 in healthy middle-aged men. British Journal of Cancer 2003; 88(11): 1682-6.

49 Giovannucci E, Pollak M, Liu Y, Platz EA, Majeed N, Rimm $\mathrm{EB}$, et al. Nutritional predictors of insulin-like growth factor I and their relationships to cancer in men. Cancer Epidemiology, Biomarkers \& Prevention 2003; 12(2): 84-9.

50 Heaney RP, McCarron DA, Dawson-Hughes B, Oparil S, Berga SL, Stern JS, et al. Dietary changes favorably affect bone remodeling in older adults. Journal of the American Dietetic Association 1999; 99(10): 1228-33.

51 Allen NE, Appleby PN, Davey GK, Key TJ. Hormones and diet: low insulin-like growth factor-I but normal bioavailable androgens in vegan men. British Journal of Cancer 2000; 83(1): $95-7$.

52 Ma J, Giovannucci E, Pollak M, Chan JM, Gaziano JM, Willett $\mathrm{W}$, et al. Milk intake, circulating levels of insulin-like growth factor-I, and risk of colorectal cancer in men. Journal of the National Cancer Institute 2001; 93(17): 1330-6.

53 Chan JM, Giovannucci E, Andersson SO, Yuen J, Adami HO, Wolk A. Dairy products, calcium, phosphorus, vitamin D, 
and risk of prostate cancer (Sweden). Cancer Causes $\mathcal{E}$ Control 1998; 9(6): 559-66.

54 Giovannucci E, Rimm EB, Wolk A, Ascherio A, Stampfer MJ, Colditz GA, et al. Calcium and fructose intake in relation to risk of prostate cancer. Cancer Research 1998; 58(3): 442-7.

55 Kristal AR, Cohen JH, Qu P, Stanford JL. Associations of energy, fat, calcium, and vitamin D with prostate cancer risk Cancer Epidemiology, Biomarkers \& Prevention 2002; 11(8): 719-25.

56 Chan JM, Giovannucci EL. Dairy products, calcium, and vitamin D and risk of prostate cancer. Epidemiologic Reviews 2001; 23(1): 87-92. 